\title{
A rare complication of Port-A-Catheter fracture
}

\author{
Asmaa Adel Milyani ${ }^{1}$, Samah M. Alharbi ${ }^{2}$, Nasser Bustanji ${ }^{3}$, Walid Asaad ${ }^{4}$, Abdulmoein Eid Al-Agha*5 \\ ${ }^{1}$ King AbdulAziz University, Faculty of Medicine, Saudi Arabia \\ ${ }^{2}$ King AbdulAziz University Hospital, Department of Paediatrics, Saudi Arabia \\ ${ }^{3}$ King AbdulAziz University Hospital, Department of Paediatric Surgery, Saudi Arabia \\ ${ }^{4}$ King AbdulAziz University Hospital, Department of Interventional Radiology, Saudi Arabia \\ ${ }^{5}$ King Abdulaziz University Hospital, Department of Paediatric Endocrinology, Saudi Arabia
}

Received: August 10, 2018

Accepted: September 25, $2018 \quad$ Online Published: October 23, 2018

DOI: $10.5430 /$ css.v5n1p1

URL: https://doi.org/10.5430/css.v5n1p1

\begin{abstract}
Background: Obtaining a central line access is an essential procedure that is necessary in various settings to facilitate the administration of medication. An implantable central line, also known as a portacath, is a subtype with a reservoir installed into a subcutaneous pocket and attached to a catheter.

Case presentation: This is a case of a fractured portacath implanted for the administration of calcium in a two year old female resulting from high syringe pressure.

Discussion: Complications range from immediate injury to vascular and surrounding structures to a delayed manifestation of infection and device malfunction. Catheter fracture in vivo is a very rare complication especially in the paediatric population. Conclusions: Appropriate size of syringe should be checked with the portacath manufacturer prior to use in order to avoid fracture as a result of high syringe pressure.
\end{abstract}

Key Words: Port-A, Catheter, Fracture, Central, Line

\section{INTRODUCTION}

Central line access is a common resort in the critical care setting due to its ease in facilitating the repetitive administration of medications directly into the systemic circulation without compromising the venous integrity of the patient. ${ }^{[1]}$ Additional uses comprise blood pressure monitoring in haemodynamically unstable patients, provision of total parenteral nutrition, and long-term provision of a reliable vascular access for extended durations. ${ }^{[2]}$ The implantable central line, or in other words a portacath, is generally installed by a surgical procedure where a reservoir is implanted in a subcutaneous pocket with an attached catheter that pierces into one of the central veins, more frequently the internal jugular and subclavian veins. ${ }^{[1,3]}$ In spite of its popular utility in clinical practice, it is associated with many complications; these are generally approached as either immediate or delayed complications. Immediate complications are largely related to the technique at the time of insertion, manifesting as a result of injury to surrounding organs and vasculature, while delayed complications are more inherent to device malfunction and the development of infection. Device dysfunction ranges from surrounding thrombosis and calcification to device fracture, ${ }^{[4]}$ the latter of which predisposing to a variety of ramifications as a result of subsequent embolisation of the detached fragment. These include but are not limited to endocarditis, cardiac perforation, arrhythmias and sepsis, therefore prompting apt recognition and appropriate inter-

\footnotetext{
* Correspondence: Abdulmoein Eid Al-Agha, Prof.; Email: aagha@kau.edu.sa; Address: King Abdulaziz University Hospital, Department of Paediatric Endocrinology, Jeddah 21589, P.O.Box 80215, Saudi Arabia.
} 
vention. ${ }^{[5]}$ We report this case of port catheter fracture due to high syringe pressure in line with the SCARE criteria. ${ }^{[6]}$

\section{CASE REPORT}

A two-year-old female with Type 2 Vitamin-D Dependent Rickets was admitted for intravenous administration of high dose calcium gluconate therapy to correct her underlying biochemical, clinical and radiological manifestations of severe rickets. An expert paediatric surgeon had placed an implantable portacath in her right internal jugular vein (IJV) uneventfully. A chest x-ray was consequently done to ensure proper placement of the catheter (see Figure 1). Daily administration of calcium gluconate at a dose of $13 \mathrm{~g}$ (1.6 $\mathrm{g} / \mathrm{kg} /$ day) diluted in Dextrose $5 \%$ solution was thereafter given at a rate of $21.6 \mathrm{ml} /$ hour (concentration was within the acceptable limits for calcium infusions) that had continued without any complications. During her third week of therapy, sudden resistance was encountered by one of the nurses upon changing the needle. Multiple trials to flush the catheter with different needle sizes were attempted to no avail, with no backflow and sustained resistance. A chest x-ray was performed for visualisation and had revealed a discontinuation of the catheter into two freestanding attachments (see Figure 2 ). She was then immediately transferred for the removal of the catheter under fluoroscopic monitoring by the paediatric surgeon in conjunction with interventional radiologists (IR). Intraoperatively, a vascular ultrasound outlined thrombosis and calcification in the right IJV where the catheter was placed (see Figure 3), the IR tried initially to retrieve it through the femoral vein but it was not possible, only for the paediatric surgeon to remove it and find that catheter was partially broken with a small attachment between the two parts that had not been visible in the X-ray (see Figure 4). Patient was soon anticoagulated with intravenous heparin. A full and complete multidisciplinary investigation had unraveled that the catheter breakage was a result of high pressure caused by the use of a 5 cc syringe for flushing the catheter, which was recognised by the nursing department. Upon extensive review of hospital policy and clinical practice guidelines, none were found for the care of an implantable portacath. Pharmacy report had confirmed that the dose of medication and rate of infusion were appropriately in line with the guidelines and therefore could not have been responsible for the breakage. For follow up, a lecture was held to educate all nurses on the recommendation regarding the subsequent use of a $10 \mathrm{cc}$ syringe when flushing implantable port catheters to avoid this adversity in the future. It is noteworthy to mention that parental consent was obtained on behalf of the patient for the publication of this article.

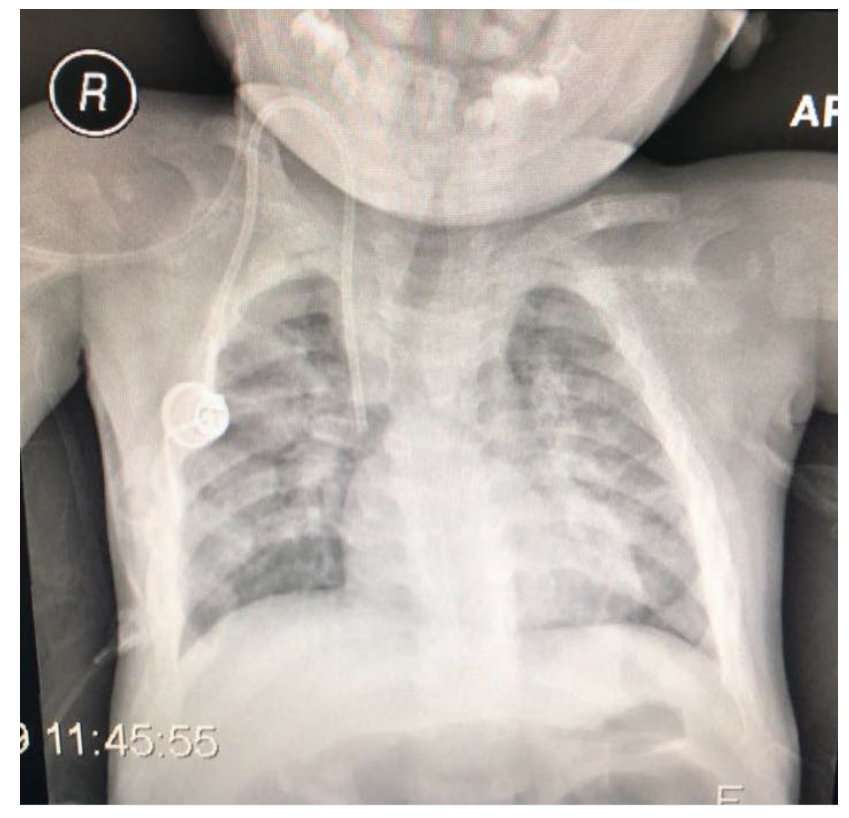

Figure 1. Chest radiograph showing the placement of the port catheter within the IJV

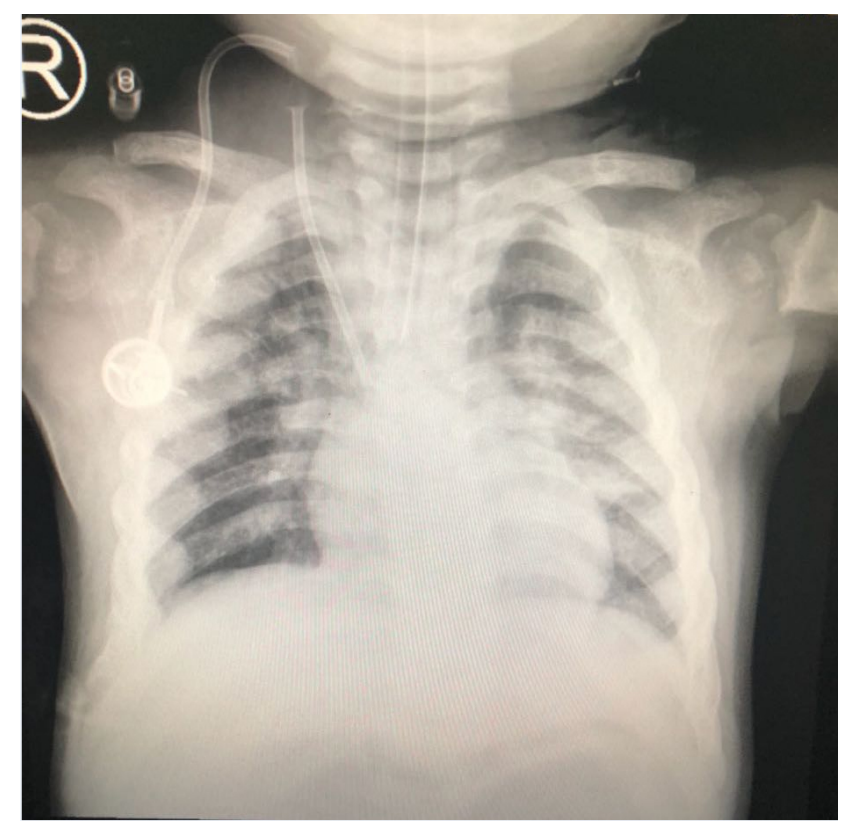

Figure 2. Chest radiograph showing dissociation of the port catheter

\section{Discussion}

Mechanical complications of port catheters such as fragment dissociation and embolisation is considered a rare adversity that has been estimated to occur at an incidence rate between $0.4 \%-1.8 \%$. ${ }^{[7]}$ However, it is a potentially life threatening incident with a reported morbidity of $71 \%$ and $38 \%$ mortality. ${ }^{[8]}$ It is most frequently witnessed in the subclavian vein in association with pinch-off syndrome, where the catheter 
is entrapped between the clavicle and the first rib, leading to its fracture. The second most common cause occurs during catheter removal, when the catheter is lodged within an ingrowth of epithelium or fibrin sheath that has formed around it. ${ }^{[9]}$ However, in our case, the port catheter was inserted in the right internal jugular vein and the fracture was not a consequence of either pinch-off syndrome or catheter entrapment. Additional causes have included shearing of the catheter lumen during needle insertion and rupture of catheter as a result of high pressure either due to a bolus infusion or as a result of incorrect use of power injectors. ${ }^{[10]}$ In other cases, catheter fracture was not attributed to any cause other than mere weakening with prolonged use, without any external signs of damage, leading to catheter fatigue and therefore a shorter lifespan. ${ }^{[11]}$ In this case, and although a power injector was not used, the catheter rupture was concluded to be a cause of high syringe pressure with the use of the standard $5 \mathrm{cc}$ syringe for flushing when a $10 \mathrm{cc}$ is currently recommended by the manufacturer. It is noteworthy to mention that almost all previous cases were reported in the adult oncology population in the setting of contrast or chemotherapeutic agent administration, and upon an extensive literature research, no cases were found in the pediatric population in association with a calcium infusion.

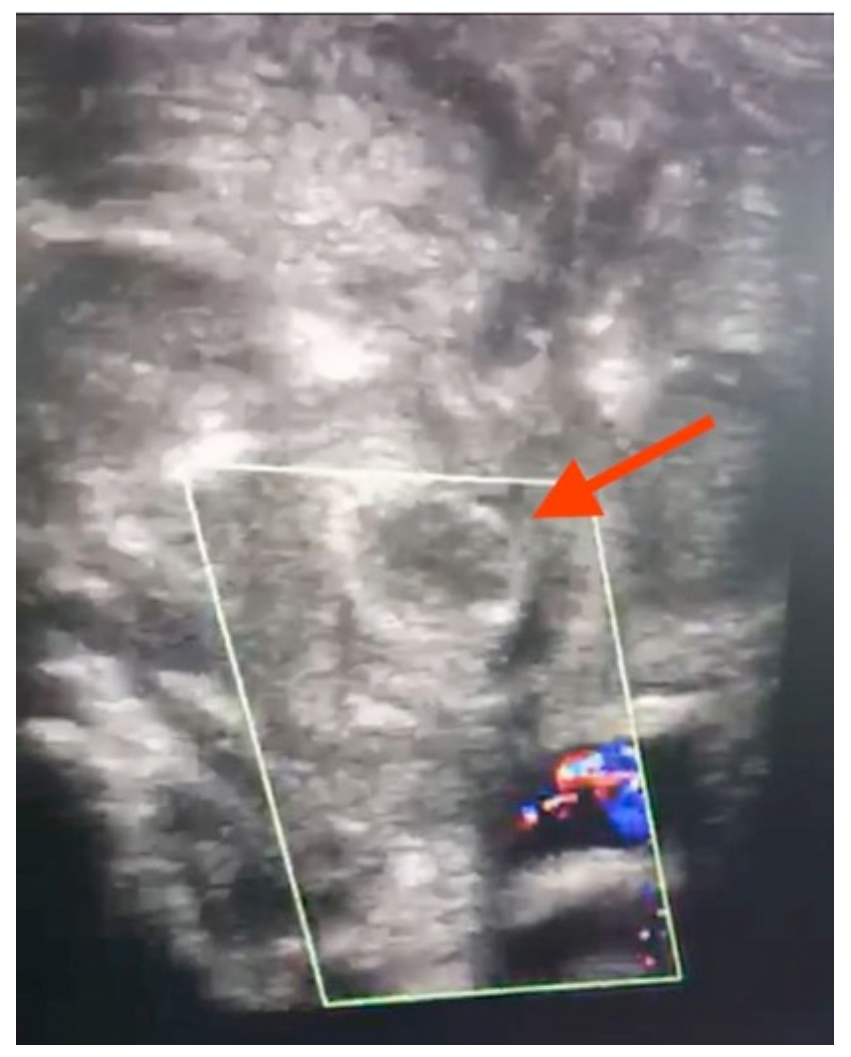

Figure 3. Intraoperative ultrasound showing right IJV thrombosis

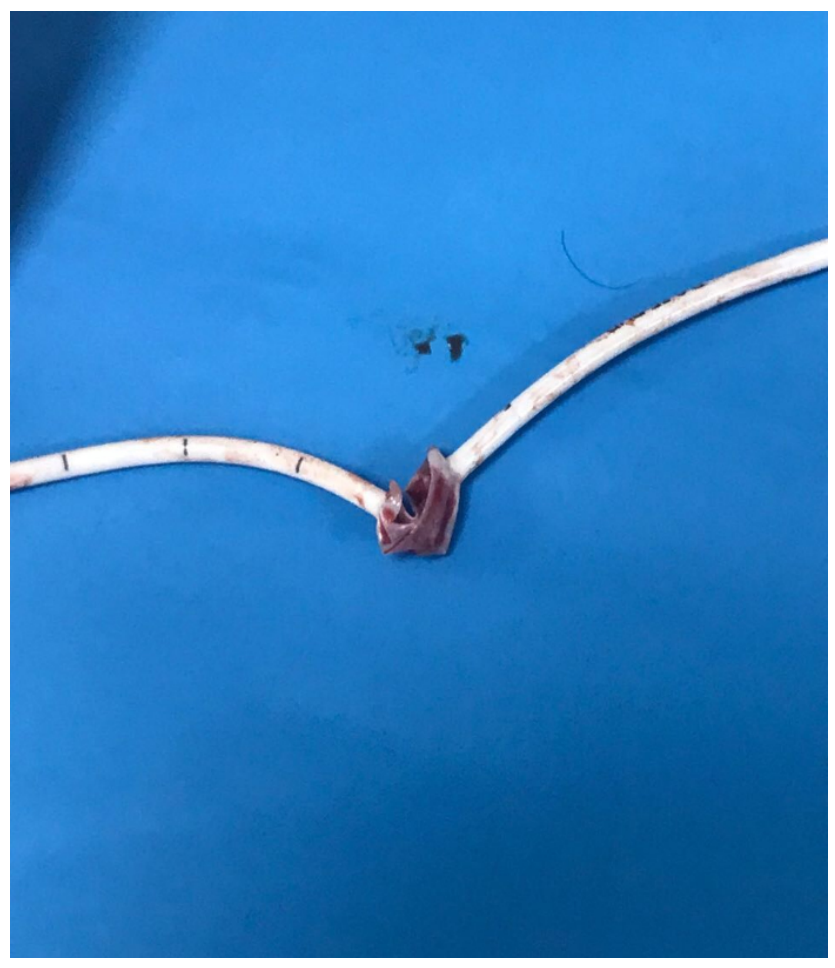

Figure 4. The catheter post surgical extraction showing dissociation with a small piece of attachment between both fragments

The discovery of catheter fragmentation in this case was completely incidental, upon encountering resistance with the attempt of a saline flush in the setting of an unblocked catheter. Other case reports have described a more symptomatic clinical presentation that might have roused suspicion, most commonly due to direct communication between the embolus and functioning anatomy. The fragment may be found anywhere along the distal course of the concerned vein; common sites are the superior vena cava, right atrium, right ventricle or even the pulmonary artery. Most of the patients present with pain at the insertion site followed by a nonfunctioning catheter. ${ }^{[12]}$ This was the case in this patient, as she was very irritable prior to the removal of the catheter. However, variability in the presenting clinical picture is documented. One case suffered signs and symptoms indicative of pneumonia in the setting of a negative chest x-ray only to confirm the diagnosis of catheter embolisation through a computed tomography (CT) scan, where two fragments were found lodged in the pulmonary artery. ${ }^{[13]}$ Another presentation was the onset of palpitations and shortness of breath once the migrating fragment had eventually arrested within the ventricles. On the other hand, some patients only manifested mild features such as a simple cough or shoulder pain. ${ }^{[14]}$ In a more uncustomary situation, the patient may remain entirely asymptomatic for an extended period of time 
that could stretch out for a number of years. One paper had reported a case that presented with a pulmonary embolism of a fractured catheter that was initially removed 11 years ago. [15]

Early extraction of the catheter alongside all fractured fragments either surgically or through a percutaneous endovascular technique is recommended in order to prevent similar situations to those mentioned above. ${ }^{[12]}$ The latter is generally preferred due to its low adverse event rate and greater than $95 \%$ success rate. ${ }^{[16]}$ Fortunately in this case, the patient was sent immediately for percutaneous retrieval under fluoroscopic monitoring before the superimposition of any further complications.

In conclusion, the associated portacath rupture had been attributed to the use of incorrect syringe size in relation to the catheter, which had inadvertently generated high syringe pressure. Therefore we recommend verifying the appropriate size for each syringe specific to the entailing manufacturer before its use in order to prevent catheter rupture as a result of high-pressure syringe.

\section{CONFlicts OF InTEREST Disclosure}

The authors declare they have no conflicts of interest.

\section{REFERENCES}

[1] Vescia S, Baumgärtner AK, Jacobs VR, et al. Management of venous port systems in oncology: a review of current evidence. Annals of Oncology. 2008; 19: 9-15. PMid: 17846025. https: //doi.org/10.1093/annonc/mdm272

[2] Thapa PB, Shrestha R, Singh DR, et al. Removal of central venous catheter fragment embolus in a young male. Kathmandu Univ Med J. 2006; 3(15): 340-1.

[3] Wolosker N, Yazbek G, Nishinari K, et al. Totally implantable venous catheters for chemotherapy: experience in 500 patients. Sao Paulo Med J. 2004; 122(4): 147-51. PMid: 15543368. https: //doi.org/10.1590/S1516-31802004000400003

[4] Kornbau C, Lee K, Hughes G, et al. Central line complications. Int J Crit Illn Inj Sci. 2015; 5(3): 170. PMid: 26557487. https: //doi.org/10.4103/2229-5151.164940

[5] Khouzam RN, Soufi MK, Weatherly M. Heparin infusion through a central line misplaced in the carotid artery leading to hemorrhagic stroke. Journal of Emergency Medicine. 2013; 45. https : //doi.org/10.1016/j.jemermed.2012.12.026

[6] Agha RA, Fowler AJ, Saeta A, et al. The SCARE Statement: Consensus-based surgical case report guidelines. Int J Surg. 2016. https://doi.org/10.1016/j.ijsu.2016.08.014

[7] Van Meter A, Zavala A, Williams UU, et al. Portal Catheter Fracture in a Pediatric Patient. Anesthesiology. 2016; 125: 1220. PMid: 27362867. https://doi.org/10.1097/ALN.00000000000012 15

[8] Deep S, Deshpande S, Howe P. Traumatic fracture of central venous catheter resulting in potential migration of distal fragment: a case report. Cases J. 2008; 1(1): 394. PMid: 19077295. https: //doi.org/10.1186/1757-1626-1-394
[9] Surov A, Wienke A, Carter JM, et al. Intravascular Embolization of Venous Catheter-Causes, Clinical Signs, and Management: A Systematic Review. J Parenter Enter Nutr. 2009; 33(6): 677-85. PMid: 19675301. https://doi.org/10.1177/0148607109335121

[10] Trotter C, Carey BE. Tearing and embolization of percutaneous central venous. Neonatal Netw. 2000; 19(8)

[11] Plumb AAO, Murphy G. The use of central venous catheters for intravenous contrast injection for CT examinations. Br J Radiol. 2011; 84(999): 197-203. PMid: 21325362. https://doi.org/10.125 9/bjr/26062221

[12] Bajpai J, Prakash V, Kant S. Study of oxidative stress biomarkers in chronic obstructive pulmonary disease and their correlation with disease severity in north Indian population cohort. Indian Chest Soc. 2017; 34(3): 324-9.

[13] Mahadeva S, Cohen A, Bellamy M. The stuck central venous catheter: Beware of potential hazards. Br J Anaesth. 2002; 89(4): 650-2. PMid: 12393372. https://doi.org/10.1093/bja/aef239

[14] Ng PK, Ault MJ, Fishbein MC. The stuck catheter: a case report. Mt Sinai J Med. 1997; 64(4-5): 350-352. PMid: 9293738.

[15] Thanigaraj S, Panneerselvam A, Yanos J. Retrieval of an IV catheter fragment from the pulmonary artery 11 years after embolization. Chest. 2000; 117(4): 1209-11. PMid: 10767267. https://doi.or g/10.1378/chest.117.4.1209

[16] Biswas S, McNerney P. Ventricular Tachycardia from a Central Line Fracture Fragment Embolus: A Rare Complication of a Commonly Used Procedure-A Case Report and Review of the Relevant Literature. Case Reports Crit Care. 2015; 2015: 1-6. Available from: http://www.hindawi.com/journals/cricc/2015/265326/ 